\title{
Value of 24-hour Delayed Film of Barium Enema for Evaluation of Colon Transit Function in Young Children with Constipation
}

\author{
Ha Yeong Yoo, ${ }^{1}$ Jae Sung Son, ${ }^{1}$ Hye Won Park, ${ }^{1}$ Byung Ok Kwak, ${ }^{1}$ Hyeong Su Kim, ${ }^{2}$ and Sun Hwan Bae ${ }^{1 *}$ \\ Departments of ${ }^{1}$ Pediatrics and ${ }^{2}$ Preventive Medicine, Konkuk University Medical Center, Konkuk University School of Medicine, Seoul, Korea
}

\begin{abstract}
Background/Aims
A colon transit time test using radio-opaque markers (CTTRM) is considered the gold standard for evaluating colon transit function. A 24-hour delayed film of barium enema (BE) has been used as a supplementary method in structural evaluations. The aim of this study was to evaluate the utility of a 24-hour delayed BE film for assessing colon transit function in young children with constipation.
\end{abstract}

\section{Methods}

In total, 93 children with constipation who performed both single-contrast BE and CTTRM were enrolled in this study. Of these, the data from 70 children were analyzed (males 33, females 37; mean age [range], $5.63 \pm 2.94$ [2-14] years). The basic principle of the study is "velocity = distance/time". Time values were identified in both studies, and the colon length and distance of barium movement were measured on the 24-hour delayed BE film. Thus, colon transit velocity values could be calculated using both methods. The correlation between colon transit velocity using a 24-hour delayed BE film versus CTTRM was analyzed statistically.

\section{Results}

Median value (interquartile range) of colon transit velocity using CTTRM was $1.57(1.07-2.89) \mathrm{cm} / \mathrm{hr}$, and that using BE of that was $1.58(0.94-2.07) \mathrm{cm} / \mathrm{hr}$. The Spearman correlation coefficient was $0.438(P<0.001)$ for the overall group. The correlation was strongest in children younger than 4 years $(r=0.537, P=0.032)$.

\section{Conclusions}

Although the correlation between BE and CTTRM was not very strong, the 24-hour delayed BE film could provide broad information about colon transit function in young children, especially those under 4 years who usually cannot undergo CTTRM.

(J Neurogastroenterol Motil 2016;22:483-489)

\section{Key Words}

Barium enema; Child; Constipation; Colon tranit

Received: August 6, 2015 Revised: January 18, 2016 Accepted: February 23, 2016

(c) This is an Open Access article distributed under the terms of the Creative Commons Attribution Non-Commercial License (http://creativecommons. org/licenses/by-nc/4.0) which permits unrestricted non-commercial use, distribution, and reproduction in any medium, provided the original work is properly cited.

*Correspondence: Sun Hwan Bae, MD, PhD

Department of Pediatrics, Konkuk University Medical Center, Konkuk University School of Medicine, 120-1 Neungdong-ro, Gwangjin-gu, Seoul 05030, Korea

Tel: +82-2-2030-7554, Fax: +82-2-2030-7748, E-mail: baedori@hanafos.com 


\section{Introduction}

Constipation is a common symptom in children and is responsible for $7 \%$ of pediatric clinic visits. ${ }^{1}$ Defecation disorders represent up to $25 \%$ of chief complaints in children who are transferred to a pediatric gastroenterology specialist. ${ }^{2,3}$ Constipation can become chronic in up to one-third of patients and persist into the adult life. ${ }^{4}$ If children under 5 years of age suffer from constipation, it is especially likely to become chronic over time, resulting in frequent visits to medical centers later in life. ${ }^{3,5}$ Thus, if young children suffer from repeated constipation events, it is important to evaluate the symptoms and to provide appropriate treatment.

There are several methods to investigate colonic motility, such as radio-opaque marker studies, scintigraphic transit studies, colonic manometry, and smart-pill motility monitoring systems. According to recent studies, there are relatively good correlations among these tests. ${ }^{6-8} \mathrm{~A}$ colon transit time (CTT) test using radio-opaque markers (CTTRM) is regarded as the gold standard for evaluating colonic motility. This test classifies constipation into three subtypes, which are then used to determine treatment. A barium enema (BE) examination has been performed to identify the organic causes of defecation disorders that begin during young childhood. A 24-hour delayed BE film has been used as an important supplementary investigation. $^{9-11}$

The aim of this study was to evaluate the utility of a 24-hour delayed BE film for colon transit function in children with constipation.

\section{Materials and Methods}

\section{Participants}

This study was conducted retrospectively. The study was approved by the institutional review board, and the need for informed consent was waived. To assess constipation that begins during young childhood, single-contrast BE and CTTRM were used at the Konkuk University Medical Center in Seoul between August 1, 2005 and July 31, 2013. Ninety-three patients with chronic constipation who underwent both BE and CTTRM were enrolled. Twenty-three children were excluded according to the exclusion criteria below, and the data from 70 children were analyzed ultimately. There were 33 males and 37 females, and their mean age was 5.63 \pm 2.94 (range, 2-14) years.

The exclusion criteria were as follows: 0 hour CTTRM in 5 patients, rectal muscle relaxation failure in 2 patients, more than 1-year interval between the BE and CTTRM tests in 6 patients, too complex or difficult to check colonic pathway on BE in 8 patients, and suspicion of organic disease on $\mathrm{BE}$ in 2 patients.

\section{Colon Transit Time Test Using Radio-opaque Markers and Barium Enema}

CTTRM and BE were performed after removing fecal impaction thoroughly within 1-2 months after the initial diagnosis. Before or during the tests, participants maintained a normal diet. From the day before the tests, medications (antibiotics, antihistamines, and antipyretics), and foods (persimmon and banana) known to affect gastrointestinal motility were avoided. If a child was suffering from another illness (upper respiratory infection, acute gastroenteritis, etc) during the test, the study was postponed.

Total CTT was performed according to a method by Metcalf et al. ${ }^{12}$ A Kolomark (MI Tech, Seoul, Korea) capsule, containing 20 radio-opaque markers per capsule, was taken at the same time each day for 3 consecutive days. A plain abdominal X-ray was taken on days 4 and 7 , and the number of remaining markers was counted. The CTT was calculated according to the following formula (Fig. 1):

CTT $=$ [sum of remaining markers $\times$ (time between administration $\div$ number of markers per capsule) $]=$ sum of remaining markers on film from days 4 and $7 \times 1.2$

For BE, laxatives, enemas, and other medicines and foods known to affect colonic motility were all stopped starting 1 day before the main procedure until the 24-hour delayed BE film was performed. After the main procedure, a 24-hour delayed abdominal $\mathrm{X}$-ray was taken in the supine position.

\section{Image Analysis of the Colon from 24-hour Delayed Barium Enema Film}

The length of the colon was measured on the 24-hour delayed $\mathrm{BE}$ film according to the assumption that each segment of the colon could be straightened (Fig. 2A). In cases where the 24-hour delayed film was not ideal for measuring the colon length, the length was measured on the supine plain abdominal X-ray taken at the initial diagnosis, and the average value from the 2 measurements was taken. For example, if the ascending colon tract was in a straight line, it was measured in a straight line from the cecum to the hepatic flexure. If the ascending colon alignment was not in a straight line, it was divided into 2 or 3 segments, and the measured values were summed. 

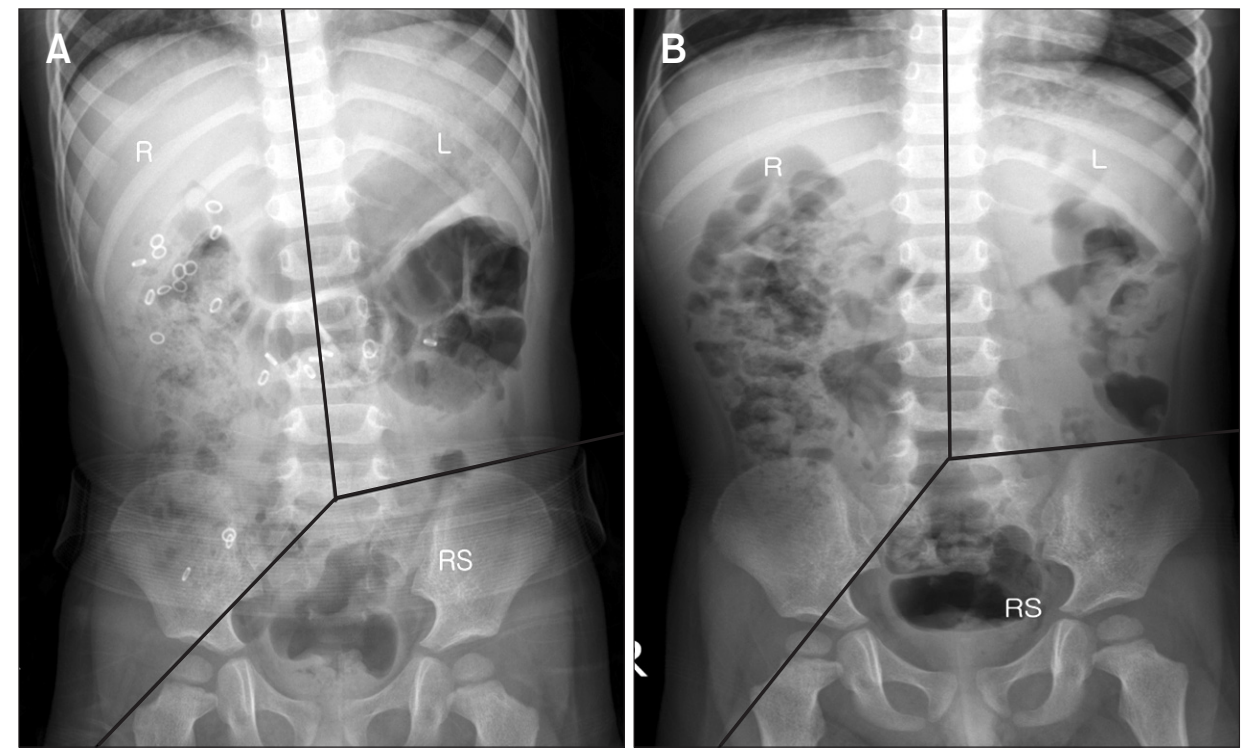

Figure 1. Abdominal X-ray on fourth day (A) and seventh day (B). This was divided into 3 colonic segments. Bony landmarks (fifth lumbar vertebra, the pelvic outlet) defined projection zones of the right colon, left colon, and rectosigmoid colon. The total number of markers in each zone were counted and multiplied by 1.2 [total colon transit time on fourth day $=(\mathrm{R}+\mathrm{L}+\mathrm{RS})$ $\times 1.2=(20+2+0) \times 1.2=22 \times$ $1.2=26.4$ hours]. $\mathrm{R}$, right colon; $\mathrm{L}$, left colon; RS, rectosigmoid colon.
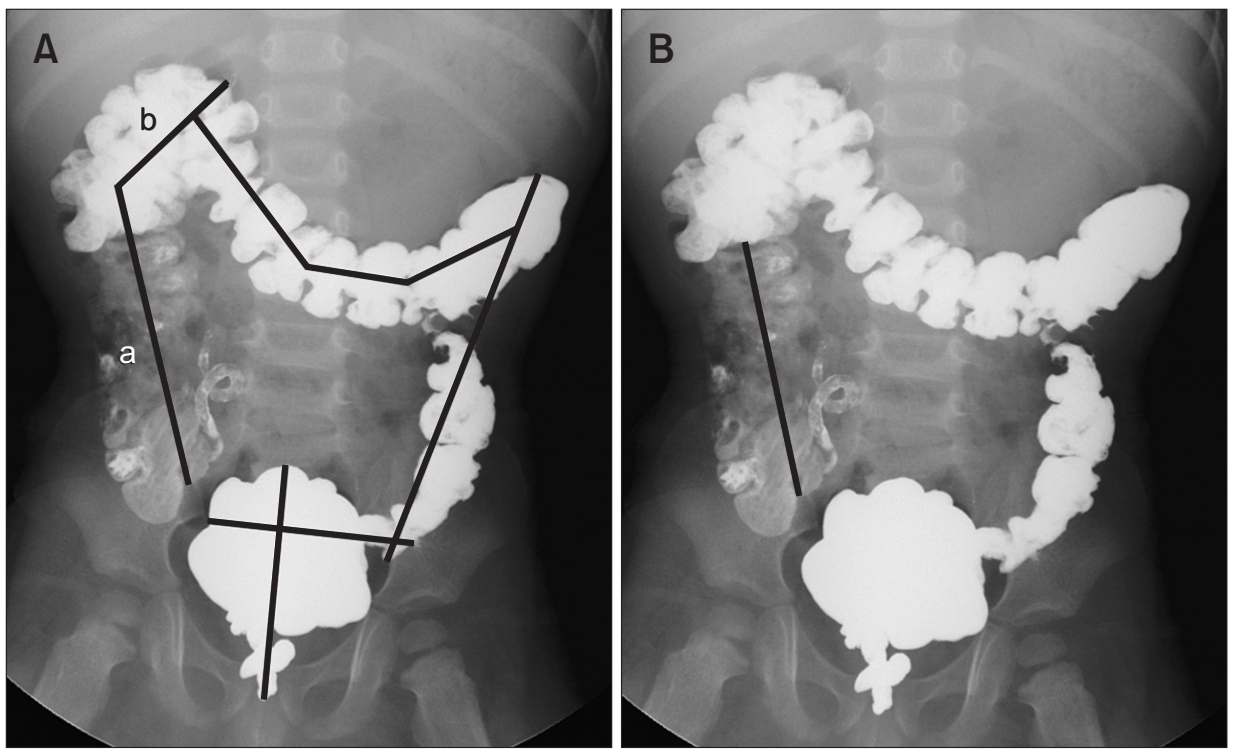

Figure 2. A 24-hour delayed barium enema film from a 4-year-old boy (A) Measurement of total colon length, length of ascending colon $=\mathrm{a}+\mathrm{b}$. (B) Estimation of the length of barium movement on the 24-hour delayed film.

The ascending colon started from the cecum and ended at the hepatic flexure. The transverse colon was from the hepatic flexure to the splenic flexure. The descending colon started from the splenic flexure and ended at the distal end of the descending colon. Sigmoid colon length was measured from the left outside of the distal descending colon to the right outside of the sigmoid colon, and the longest straight section was measured. The length of the rectum was measured from the most proximal end to the most distal point of the rectum at which barium was observed. If barium was not observed, it was measured from the proximal end of the rectum to the distal outside of the symphysis pubis.
The distance of barium movement was measured from the proximal end of the colon where barium filled just at the end of the main study of $\mathrm{BE}$ to the most proximal area where barium remained vivid 24 hours later (Fig. 2B). In order to clarify the barium density on the 24-hour delayed BE film, we applied the self-developed numeric scale. The barium density was graded 0-10 according to its brightness. The brightness without the barium was defined as 0 , and the brightest density of barium-filled colon during the main procedure of barium enema was defined as 10. Defining the area where barium remained vivid on the 24-hour delayed BE film, the brightness of the area was more than 7, and barium filled 
Table 1. Colon Transit Velocity Between Radio-opaque Markers Colon Transit Time Test and Barium Enema

\begin{tabular}{|c|c|c|c|}
\hline & Colon transit velocity $(\mathrm{cm} / \mathrm{hr})$ & Distance $(\mathrm{cm})$ & Time (hr) \\
\hline CTT test & CTT velocity $=\frac{\text { Colon length }}{\text { CTT }}$ & Colon length & $\mathrm{CTT}=$ number of markers $\times 1.2$ \\
\hline $\mathrm{BE}$ & BE velocity $=\frac{\text { Length of barium movement }}{\text { Time }(24 \mathrm{hr})}$ & Length of barium movement & 24 \\
\hline
\end{tabular}

CTT, colon transit time; BE, barium enema.

Table 2. Comparing Average Values of Colon Transit Time Test and Barium Enema

\begin{tabular}{lcccc}
\hline & Total $(\mathrm{N}=70)$ & $<4$ yr $(\mathrm{n}=16)$ & $\geq 4$ yr $(\mathrm{n}=54)$ & $P$-value \\
\hline Colon length $(\mathrm{cm})$ & $59.00(53.75-64.00)$ & $54.00(51.00-59.00)$ & $61.00(55.00-66.00)$ & 0.002 \\
CTT $(\mathrm{hr})$ & $36.00(22.50-54.30)$ & $29.40(24.30-46.80)$ & $37.80(21.30-57.90)$ & 0.429 \\
CTT velocity $(\mathrm{cm} / \mathrm{hr})$ & $1.57(1.07-2.89)$ & $1.74(1.08-2.31)$ & $1.48(1.03-2.93)$ & 0.922 \\
BE velocity $(\mathrm{cm} / \mathrm{hr})$ & $1.58(0.94-2.07)$ & $1.76(0.39-2.02)$ & $1.55(0.94-2.11)$ & 0.817 \\
\hline
\end{tabular}

CTT, colon transit time; BE, barium enema.

Values are expressed as median value (interquartile range).

more than three quarters of the colonic diameter. To reduce intraobserver variation, two of the authors participated and discussed this process.

\section{Formula of Colon Transit Velocity}

The result of a CTT test is expressed as a time parameter, and the time value of the 24-hour delayed BE film was defined as 24 hours. Because CTTRM and BE were performed on the same patient, the measured total colon length on the 24-hour delayed film could be applied to both tests for colon transit velocity. On the basis of the fundamental formula, "velocity = distance/time", colon transit velocity using the CTTRM test (CTT velocity) and that using $\mathrm{BE}$ (BE velocity) could be calculated (Table 1).

\section{Statistical Methods}

Statistical analyses were performed using the SPSS software (version 21.0; IBM Co, Armonk, NY, USA). Shapiro-Wilk test was used for assessing the normality of data. Mann-Whitney $U$ test was applied for comparison of average values of the subgroups, and variables are presented as median (interquartile range). The relationships between CTT velocity and BE velocity were calculated using the Spearman correlation test. A value of $P<0.05$ was considered statistically significant.

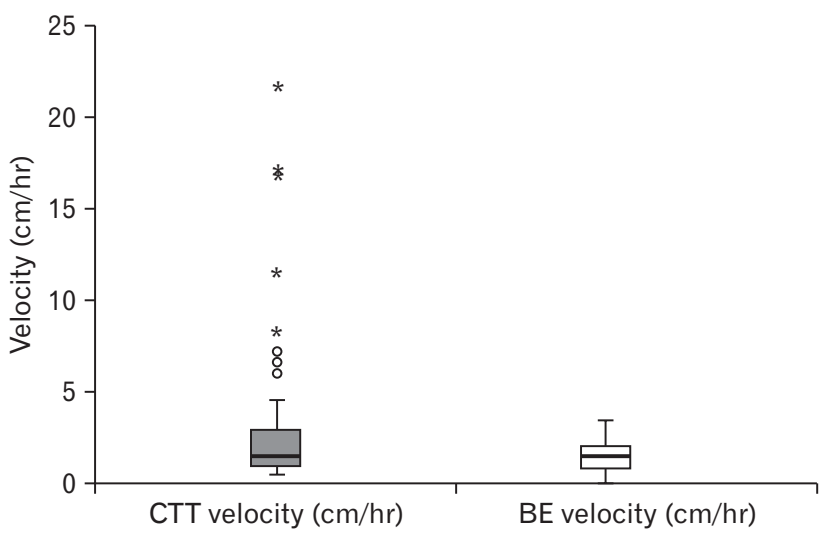

Figure 3. A box plot representing the median and interquartile range for colonic velocity in colon transit time (CTT) test and barium enema (BE). Eight outliers were shown outside the whiskers.

\section{Results}

\section{Clinical Data}

The clinical data of the entire group and subgroups are summarized in Table 2. The subjects were divided into 2 subgroups in terms of age: $<4$ years of age, over $\geq 4$ years of age and the clinical parameters (colon length, CTT time, CTT velocity, and BE velocity) were assessed using the Mann-Whitney U test. Among them, the difference was significant in colon length only $(P<$ $0.001)$. CTT velocity was $1.57(1.07-2.89) \mathrm{cm} / \mathrm{hr}$ (median value $[\mathrm{IQR}$, interquartile range]), and BE velocity was 1.58 (0.94-2.07) 
Table 3. The Correlation of Colon Transit Velocity Between Colon Transit Time Test and Barium Enema on 24-hour Delayed Barium Enema Film

\begin{tabular}{|c|c|c|c|c|c|}
\hline & Number & $R$ & $P$-value & $r^{a}$ & $P$-value \\
\hline All patients & 70 & 0.438 & $<0.001$ & 0.431 & $<0.001$ \\
\hline \multicolumn{6}{|l|}{ Sex } \\
\hline Male & 33 & 0.454 & 0.008 & 0.454 & 0.009 \\
\hline Female & 37 & 0.428 & 0.008 & 0.423 & 0.010 \\
\hline \multicolumn{6}{|l|}{ Age } \\
\hline$<4 \mathrm{yr}$ & 16 & 0.537 & 0.032 & & \\
\hline$\geq 4 \mathrm{yr}$ & 54 & 0.423 & 0.001 & & \\
\hline Except 8 outliers & 62 & 0.444 & $<0.001$ & & \\
\hline$<4$ yr & 15 & 0.606 & 0.017 & & \\
\hline$\geq 4 \mathrm{yr}$ & 47 & 0.397 & 0.006 & & \\
\hline \multicolumn{6}{|l|}{ Colon transit type } \\
\hline Normal transit type & 24 & -0.074 & 0.733 & & \\
\hline Slow transit type & 10 & -0.141 & 0.697 & & \\
\hline Outlet obstructive type & 36 & 0.490 & 0.002 & & \\
\hline
\end{tabular}

${ }^{a} r$ is a partial correlation coefficient adjusted by age.

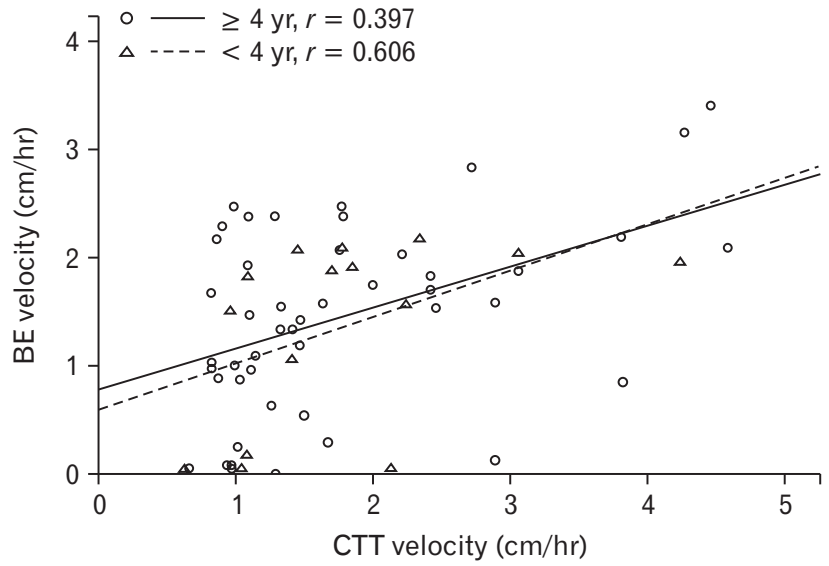

Figure 4. Graph showing the relationship between colon transit time (CTT) test using radio-opaque markers colon transit velocity and $\mathrm{BE}$ colon transit velocity in the subjects except the values of outliers $(\mathrm{n}=$ 62). Subjects younger than 4 years showed higher positive correlation (n $=15, r=0.606 ; P=0.017)$ than those over 4 years of age $(\mathrm{n}=$ $47, r=0.397 ; P<0.001)$.

cm/hr (Fig. 3).

\section{Correlation Between Colon Transit Time and Barium Enema Velocities}

The Spearman correlation coefficient $(r)$ between CTT velocity and BE velocity was $0.438(P<0.001)$ in the entire cohort, 0.454 ( $P=0.008)$ for males, and $0.428(P=0.008)$ for females. The age-adjusted correlation coefficient in the entire group decreased slightly, to $0.431(P<0.001)$, and which was $0.454(P=0.009)$ for males and $0.423(P=0.010)$ for females (Table 3$)$. Considering age, the correlation coefficient was $0.423(P=0.001)$ for patients over 4 years of age $(n=54)$ and $0.537(P=0.032)$ for those under 4 years of age $(\mathrm{n}=16)$. Considering outlier in Figure 3 , except for 8 patients $(n=62, M / F 31 / 31)$, the correlation coefficient was slightly higher to $0.444(P<0.001)$ in the entire cohort, which was $0.397(P=0.006)$ for patients over 4 years of age $(n=$ $47)$ and $0.606(P=0.017)$ for those under 4 years of age $(n=15)$ (Fig. 4).

\section{Discussion}

Although there are now several methods for determining CTT, CTTRM is still considered the gold standard, and has been used most widely in both adults and children. ${ }^{13,14}$ On the basis of CTTRM, functional constipation can be classified into the normal colon transit type, outlet obstruction type, and slow transit type. ${ }^{6,15}$ This distinction may be helpful for establishing an accurate diagnosis and effective treatment. ${ }^{7,16,17}$ In the Arhan method of CTTRM, radio-opaque markers are ingested and abdominal $\mathrm{X}$-rays are performed every 24 hours until all markers pass. ${ }^{18}$ In the Metcalf method, radio-opaque markers are ingested each day at the same time for 3 consecutive days. Then, an abdominal X-ray is taken on the fourth day, and then at 3-day intervals until all markers pass. ${ }^{12}$ In this study, CTTRM was performed with the Metcalf method. However, CTTRM is typically not easy to perform in children, especially in children younger than 4 years.

A single-contrast barium enema study was usually performed 
in children with constipation that began at an early age. A 24-hour delayed BE film has been used as an important supplementary finding for the diagnosis or suspicion of organic disease, such as Hirschsprung's disease (congenital megacolon), internal anal sphincter achalasia, and anal stenosis. ${ }^{9,19}$

Generally, larger particles move faster than smaller particles in the gastrointestinal tract. In this study, the values of lower and upper quartiles of CTT velocities were higher than that of BE velocities, and this result coincided with the above-mentioned scientific principle. We think this finding gives objective rationality to this study.

In this study, the colon transit function assessed by the 24-hour delayed BE film had a meaningful correlation with that by CTTRM, which is considered the gold standard method to evaluate colonic motility. This correlation was stronger in children younger than 4 years who cannot undergo standard CTTRM. We consider that this finding adds a functional concept to the structural concept of the 24-hour delayed BE film.

A 24-hour delayed BE film does not give as refined information such as subtype classification, or prediction of prognosis, as does CTTRM. However, it can provide broad information about colon transit function, and this will be helpful for guiding treatment in young children. Recently, the concept that prolonged CTT might predict a poor prognosis was proposed. ${ }^{20}$

We do not know exactly why the correlation between the two methods weakened with age. However, CTT usually increases with the age of the child. In addition, the effects of particle size difference on the movement between barium and the radio-opaque markers might be exaggerated in cases of slow movement. We suggest that both effects might have affected the results.

In this study, the length of the colon was calculated according to the assumption that the colon runs in a linear pathway. This might underestimate the actual length of the colon, especially the sigmoid colon. However, we checked the correlation of colon transit velocity between BE and CTTRM in each patient by applying the same measured colon length value. Thus, we do not think that this assumption affected our results. Some may argue that inter-observer variation exists in defining the distance of barium movement on the 24-hour delayed BE films. For this, we proposed a numeric scale. We do not think it can eliminate inter-observer variations completely. However, we think it can contribute to reducing interobserver variations. In addition, many children were excluded from the analysis in this study because, for example, their colonic pathway was too complex or difficult to measure on the 24-hour delayed BE film or initial abdominal X-ray. These limitations need to be overcome by further studies.
In conclusion, the 24-hour delayed BE film could provide broad information about colon transit function in young children, especially those under 4 years who usually cannot undergo CTTRM.

\section{Financial support: None.}

\section{Conflicts of interest: None.}

Author contributions: Ha Yeong Yoo, Hye Won Park, Hyeong Su Kim, Byung Ok Kwak, and Sun Hwan Bae were responsible for data collection; Ha Yeong Yoo, Jae Sung Son, and Sun Hwan Bae were responsible for drafting the manuscript; and all authors were responsible for study conception, data-analysis, and interpretation.

\section{References}

1. Loening-Baucke V. Chronic constipation in children. Gastroenterology 1993;105:1557-1564.

2. Levine MD. Children with encopresis: a descriptive analysis. Pediatrics 1975;56:412-416.

3. Youssef NN, Di Lorenzo C. Childhood constipation: evaluation and treatment. J Clin Gastroenterol 2001;33:199-205.

4. van Ginkel R, Reitsma JB, Büller HA, Taminiau JA, Benninga MA. Childhood constipation: longitudinal follow-up beyond puberty. Gastroenterology 2003;125:357-363.

5. Chitkara DK, Talley NJ, Locke GR, et al. Medical presentation of constipation from childhood to early adulthood: a population-based cohort study. Clin Gastroenterol Hepatol 2007;5:1059-1064.

6. Southwell BR, Clarke MC, Sutcliffe J, Hutson JM. Colonic transit studies: normal values for adults and children with comparison of radiological and scintigraphic methods. Pediatr Surg Int 2009;25:559-572.

7. Belkind-Gerson J, Tran K, Di Lorenzo C. Novel techniques to study colonic motor function in children. Curr Gastroenterol Rep 2013;15:1-7.

8. Camilleri M, Thorne NK, Ringel Y, et al. Wireless pH-motility capsule for colonic transit: prospective comparison with radiopaque markers in chronic constipation. Neurogastroenterol Motil 2010;22:874-e233.

9. Yik YI, Cook DJ, Veysey DM, et al. How common is colonic elongation in children with slow-transit constipation or anorectal retention? J Pediatr Surg 2012;47:1414-1420.

10. Staiano A, Andreotti MR, Greco L, Basile P, Auricchio S. Long-term follow-up of children with chronic idiopathic constipation. Dig Dis Sci 1994;39:561-564.

11. Reid JR, Buonomo C, Moreira C, Kozakevich H, Nurko SJ. The barium enema in constipation: comparison with rectal manometry and biopsy to exclude Hirschsprung's disease after the neonatal period. Pediatr Radiol 2000;30:681-684.

12. Metcalf AM, Phillips SF, Zinsmeister AR, MacCarty RL, Beart RW, Wolff BG. Simplified assessment of segmental colonic transit. Gastroen- 
terology 1987;92:40-47.

13. de Lorijn F, van Wijk MP, Reitsma JB, van Ginkel R, Taminiau J, Benninga MA. Prognosis of constipation: clinical factors and colonic transit time. Archi Dis Child 2004;89:723-727.

14. Szarka LA, Camilleri M. Methods for the assessment of small-bowel and colonic transit. Semin Nucl Med: Elsevier 2012:113-123.

15. Bouchoucha M, Prado J, Chtourou L, Devroede G, Atanassiu C, Benamouzig R. Non-compliance does not impair qualitative evaluation of colonic transit time. Neurogastroenterol Motil 2011;23:103-108.

16. Choi JE, Choi IJ, Lee JA, Kim SM, Jeong JH, Lee JH. Colonic transit time in chronic constipated patients. Korean J Pediatr 2001;44:752-757.
17. Kim ER, Rhee PL. How to interpret a functional or motility test-colon transit study. J Neurogastroenterol Motil 2012;18:94.

18. Arhan P, Devroede G, Jehannin B, et al. Segmental colonic transit time. Dis Colon Rectum 1981;24:625-629.

19. Wong C, Lau C, Chung P, Lam W, Wong K, Tam P. The value of the 24-h delayed abdominal radiograph of barium enema in the diagnosis of Hirschsprung's disease. Pediatr Surg Int 2015;31:11-15.

20. Tabbers M, DiLorenzo C, Berger M, et al. Evaluation and treatment of functional constipation in infants and children: evidence-based recommendations from ESPGHAN and NASPGHAN. J Pediatr Gastroenterol Nutr 2014;58:258-274. 